\title{
Systematic review and meta-analysis of the correlation between intestinal flora and gestational diabetes mellitus
}

\author{
Qiong Ding, Ying Hu, Yun Fu, Liyi Qian \\ Department of Gynecology and Obstetrics, Zhejiang Hospital, Hangzhou, China \\ Contributions: (I) Conception and design: Q Ding, L Qian; (II) Administrative support: Y Hu; (III) Provision of study materials or patients: Q Ding, \\ Y Hu, Y Fu; (IV) Collection and assembly of data: All authors; (V) Data analysis and interpretation: Q Ding, Y Fu, L Qian; (VI) Manuscript writing: \\ All authors; (VII) Final approval of manuscript: All authors. \\ Correspondence to: Liyi Qian. Department of Gynecology and Obstetrics, Zhejiang Hospital, No. 1229, Gudun Road, Sandun Town, Xihu District, \\ Hangzhou, China. Email: qly361415045@163.com.
}

Background: A meta-analysis was conducted on the correlation between intestinal flora and gestational diabetes mellitus (GDM) to provide a theoretical basis for the treatment of GDM.

Methods: The PubMed, Embase, MEDLINE, Ovid, Springer, and Web of Science databases were searched from the establishment of the databases to December 31, 2020, to retrieve randomized control trials (RCTs) involving GDM patients. The Cochrane Handbook for Systematic Reviews of Intervention 5.0.2 was used to assess the bias risk of the included articles, and Rev Man 5.3 was used for the meta-analysis.

Results: A total of 7 studies were included in the meta-analysis, comprising 665 study participants. The meta-analysis results showed that the GDM patients in the experimental group had a lower level of Bifidobacterium [MD (mean difference) $=-2.49 ; 95 \%$ confidence interval (CI): -3.54 to $-1.45 ; Z=4.66$; $\mathrm{P}<0.00001]$, Lactobacillus $[\mathrm{MD}=-1.69 ; 95 \% \mathrm{CI}:-1.84$ to $-1.53 ; \mathrm{Z}=20.66 ; \mathrm{P}<0.00001]$, Bacteroides $[\mathrm{MD}=-1.17$; 95\% CI: -1.45 to $-0.89 ; \mathrm{Z}=8.15 ; \mathrm{P}<0.00001]$, Bacteroidetes $[\mathrm{MD}=-1.22 ; 95 \% \mathrm{CI}:-1.71$ to $-0.72 ; \mathrm{Z}=4.81$; $\mathrm{P}<0.00001]$, and a higher level of Enterobacter $[\mathrm{MD}=1.79 ; 95 \% \mathrm{CI}: 1.13$ to $2.45 ; \mathrm{Z}=5.3 ; \mathrm{P}<0.00001]$, Enterococcus $[\mathrm{MD}=1,29 ; 95 \% \mathrm{CI}: 0.98$ to $1.6 ; \mathrm{Z}=8.06 ; \mathrm{P}<0.00001]$, Fusobacterium $[\mathrm{MD}=0.03 ; 95 \%$ CI: -0.13 to $0.19 ; \mathrm{Z}=0.37 ; \mathrm{P}=0.71]$, tumor necrosis factor alpha (TNF- $\alpha$ ) $[\mathrm{MD}=113.66 ; 95 \% \mathrm{CI}$ : 52.01 to 175.31 ; $\mathrm{Z}=3.61 ; \mathrm{P}=0.0003$ ], interleukin (IL) -17 [MD =37.92; 95\% CI: 29.74 to $46.1 ; \mathrm{Z}=9.09 ; \mathrm{P}<0.00001]$, and IL-6 [MD $=66.38 ; 95 \%$ CI: 33.6 to $99.15 ; Z=3.97 ; \mathrm{P}<0.0001]$ than those in the control group; however, no statistically significant difference was found in relation to Fusobacterium between the experimental group and the control group.

Discussion: Intestinal microecological changes are closely related to the occurrence of GDM in our study, which manifested as a decrease in the level of probiotics, an increase in the level of intestinal bacteria and other strains, and an increase in the level of inflammatory factors. Thus, special attention should be paid to changes in patients' intestinal flora to prevent GDM.

Keywords: Gestational diabetes mellitus (GDM); intestinal flora; estrogen; progesterone; cortisol

Submitted Jul 12, 2021. Accepted for publication Sep 09, 2021.

doi: 10.21037/apm-21-2061

View this article at: https://dx.doi.org/10.21037/apm-21-2061

\section{Introduction}

Gestational diabetes mellitus (GDM) is a disease unique to women during pregnancy. More than $80 \%$ of pregnant women with diabetes have GDM, and fewer than $20 \%$ of these women have diabetes before pregnancy (1). The incidence of GDM is reported to range from $1 \%$ to $14 \%$ worldwide (2). In China, the incidence is approximately $1 \%$ to $5 \%$, but it has increased significantly in recent years (3). The glucose metabolism of most GDM patients returns to normal after delivery, but the chance of developing type II 
diabetes increases (4). Thus, the disease has a great effect on the outcome of a pregnancy and the health of the offspring.

During early and midterm pregnancy, the fetus's demand for nutrients increases as the gestational weeks increase, and the fetus obtains glucose from the mother through the placenta, which is the main source of energy (5). The plasma glucose level of pregnant women decreases as the pregnancy progresses, and fasting blood glucose is reduced by approximately $10 \%$. This is partly because estrogen and progesterone increase the utilization of glucose by the mother (6). Thus, the ability to clear glucose during pregnancy is stronger than that during nonpregnancy. The fasting blood sugar of pregnant women is lower than that of nonpregnant women, which is the pathological basis for the susceptibility to low blood sugar and ketoacidosis (7). During middle and late pregnancy, anti-insulin like substances, such as placental lactogen, estrogen, progesterone, cortisol, and placental insulinase, increase, which reduces the sensitivity of pregnant women to insulin. To maintain a normal level of glucose metabolism, there is an increased need for insulin. For pregnant women with restricted insulin secretion, the blood sugar level rises, which aggravates the original diabetes or leads to GDM. Additionally, women's weight increases during pregnancy, and their resistance to insulin is raised. Once the body's insulin level cannot maintain normal glucose metabolism, diabetes occurs. A comparison of the levels of intestinal flora during early and late pregnancy revealed that the occurrence of GDM was associated with the level of certain flora (8).

To further determine the correlation between the intestinal flora and GDM, randomized control trials (RCTs) involving intestinal flora and GDM were identified, and a systematic meta-analysis was conducted. We present the following article in accordance with the PRISMA reporting checklist (available at https://dx.doi.org/10.21037/apm-21-2061).

\section{Methods}

\section{Literature inclusion and exclusion criteria}

To be eligible for inclusion in the meta-analysis the, articles had to meet the following inclusion criteria: (I) involve female participants who were pregnant and who either had GDM (the experimental group) or normal glucose tolerance (the control group); (II) involve a RCT and be written in English; (III) in relation to the experimental group, include results related to fresh feces that had been collected in an aseptic anaerobic tank in the early morning to detect the intestinal flora, and $5 \mathrm{~mL}$ of fasting venous blood that had been drawn to detect inflammatory factors; (IV) in relation to the control group, include results related to fresh feces that had been collected in the early morning to detect intestinal flora and $3 \mathrm{~mL}$ of fasting venous blood that had been drawn to detect inflammatory factors $(V)$ further, had comparable baseline data between the experimental group and the control group; and (VI) had outcome indicators that included advocacy strain and line tube inflammatory factors.

Conversely, articles were excluded from the meta-analysis if they met any of the following exclusion criteria: (I) were non-RCTs, such as retrospective studies, case reports, and cohort studies; (II) comprised subjects that were animals, cells, etc.; (III) had not been published, such as these, or were not in the English language; (IV) were irrelevant; and/or (V) contained incomplete research data.

\section{Literature retrieval}

The PubMed, Embase, MEDLINE, Ovid, Springer, and Web of Sciences databases were searched from the dates of establishment of the databases to December 31, 2020, using the following search terms: "Intestinal flora," "Gestational diabetes mellitus," and "Meta-analysis." For each database, a joint search strategy of free words and subject words was adopted. After confirmation, the references were tracked using the search engine, and the latest research progress was obtained by contacting experts and researchers in the field.

\section{Literature screening}

The literature screening comprised three steps. First, studies that were not related to this area of research were excluded by reading the titles and abstracts. Second, studies that did not meet the inclusion or exclusion criteria were excluded through a reading of the full texts of the articles. Third, a quality evaluation was performed in which two senior experts independently screened the abstracts and full texts of the relevant articles. Three preliminary experiments were performed before the screening. Inconsistencies between the experts were resolved through discussion, and if a consensus could not be reached, a third expert was invited to arbitrate.

\section{Data extraction}

The two assessors independently used the self-developed data extraction table to extract data, which was then crosschecked after the extraction. The information extracted 


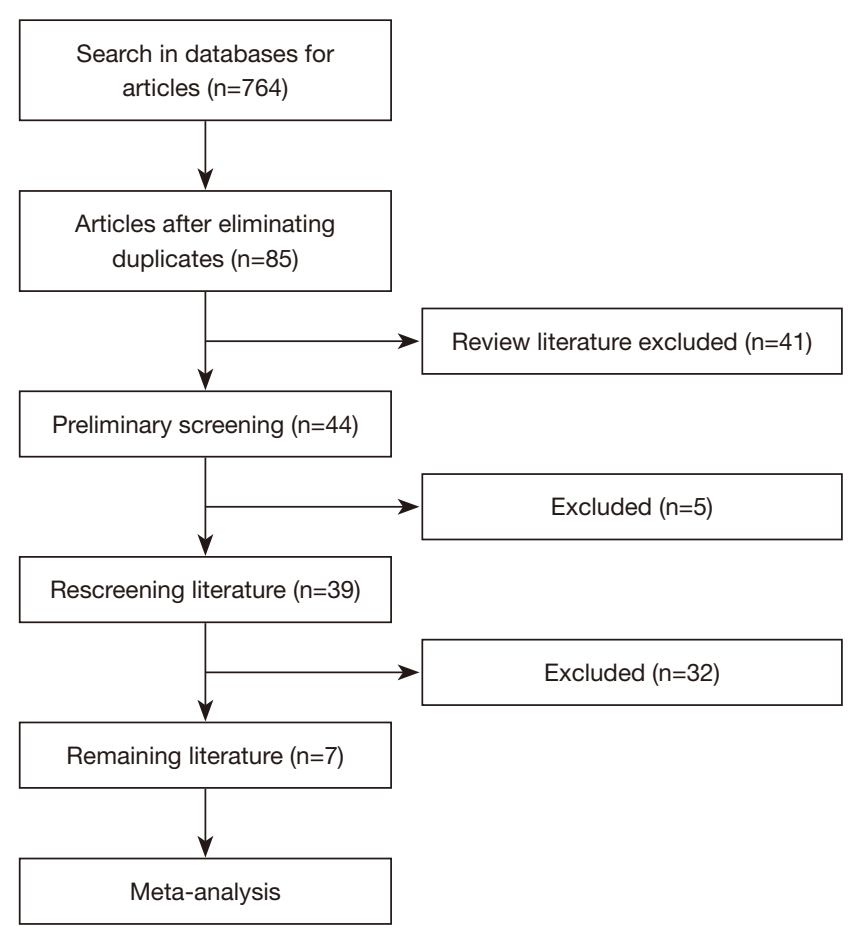

Figure 1 The literature retrieval process.

included: (I) the title of the article, first author (only 1 name included), the year of publication, and the publication journal; (II) the age, gender, sample size, and baseline comparability of the subjects; (III) the intervention measures and control measures; and (IV) the outcome indexes.

\section{Quality evaluation}

The bias risks of the included articles were assessed according to criteria provided in the Cochrane Handbook 5.0.2, which factored in selection bias, implementation bias, measurement bias, follow-up bias, and other biases including whether a random sequence had been used, whether allocation concealment had been adopted, whether a blind method had been used for the subjects; whether a blind method had been used for the outcome assessor; whether the data were complete; and whether there was selective reporting. Any inconsistency was solved by discussion or by asking another researcher to arbitrate.

\section{Statistical methods}

The Cochrane Handbook 5.0.2 was used to assess the bias risk of the articles, and Review Manager (RevMan) 5.3 was used for the meta-analysis. According to the analysis results, forest plots and funnel charts were output. In the meta-analysis, the literature was tested for heterogeneity, and the $\mathrm{I}^{2}$ test was used. If $\mathrm{I}^{2} \geq 50 \%$ and $\mathrm{P}<0.05$, there was homogeneity among the included articles, and the fixedeffects model (FEM) was used for the meta-analysis. If the $\mathrm{I}^{2}<50 \%$ and $\mathrm{P}>0.05$, there was heterogeneity among the included articles, and the random-effects models (REM) was used for the meta-analysis. The binary variables, including the incidence of adverse reactions, the relative risk (RR) of the effect size, and the $95 \%$ confidence intervals (95\% CIs) were calculated. For continuous variables, such as conversion time, the weighted mean difference (WMD) was used as the effect size. If the units of the indicators were different, the standardized mean difference (SMD) was used as the effect size, and the $95 \%$ CI: was calculated. A U test ( $Z$ test) was used to judge whether there was statistical significance, and the $\mathrm{P}$ value was calculated according to the $u$ value. $\alpha=0.05$ was taken as the test standard, and a $P$ value $<0.05$ was used as the threshold for significance. For binary variables, if the $95 \%$ CI did not contain 1 (i.e., $95 \%$ CI: $>1$ or $<1$ ), it was equivalent to $\mathrm{P}<0.05$. For continuous variables, if the $95 \% \mathrm{CI}$ did not contain 0 (i.e., $95 \% \mathrm{CI}:>0$ or $<0)$, it was considered equivalent to $\mathrm{P}<0.05$.

\section{Results}

\section{Basic characteristics of the included literature}

Initially, 764 documents were identified, including 133 from the PubMed database, 79 from the Embase database, 120 from the MEDLINE database, 101 from the Springer database, 156 from the Ovid database, and 175 from the Web of Science database. Next, 679 duplicates were eliminated, leaving 85 articles remaining. After a reading of the titles and abstracts, 44 articles were further eliminated according to the literature inclusion and exclusion criteria, and 39 were identified. Finally, after the 2 researchers read and cross-examined the full text, a total of 7 documents were included in the meta-analysis. They were all RCTs, published before 2020, and comprised a total of 665 participants. The baseline data, such as the age, of the experimental group and the control group were comparable (see Figure 1 and Table 1).

\section{Bias-risk assessment}

The Cochrane Handbook for Systematic Reviews of 
Table 1 Basic characteristics of the included literature

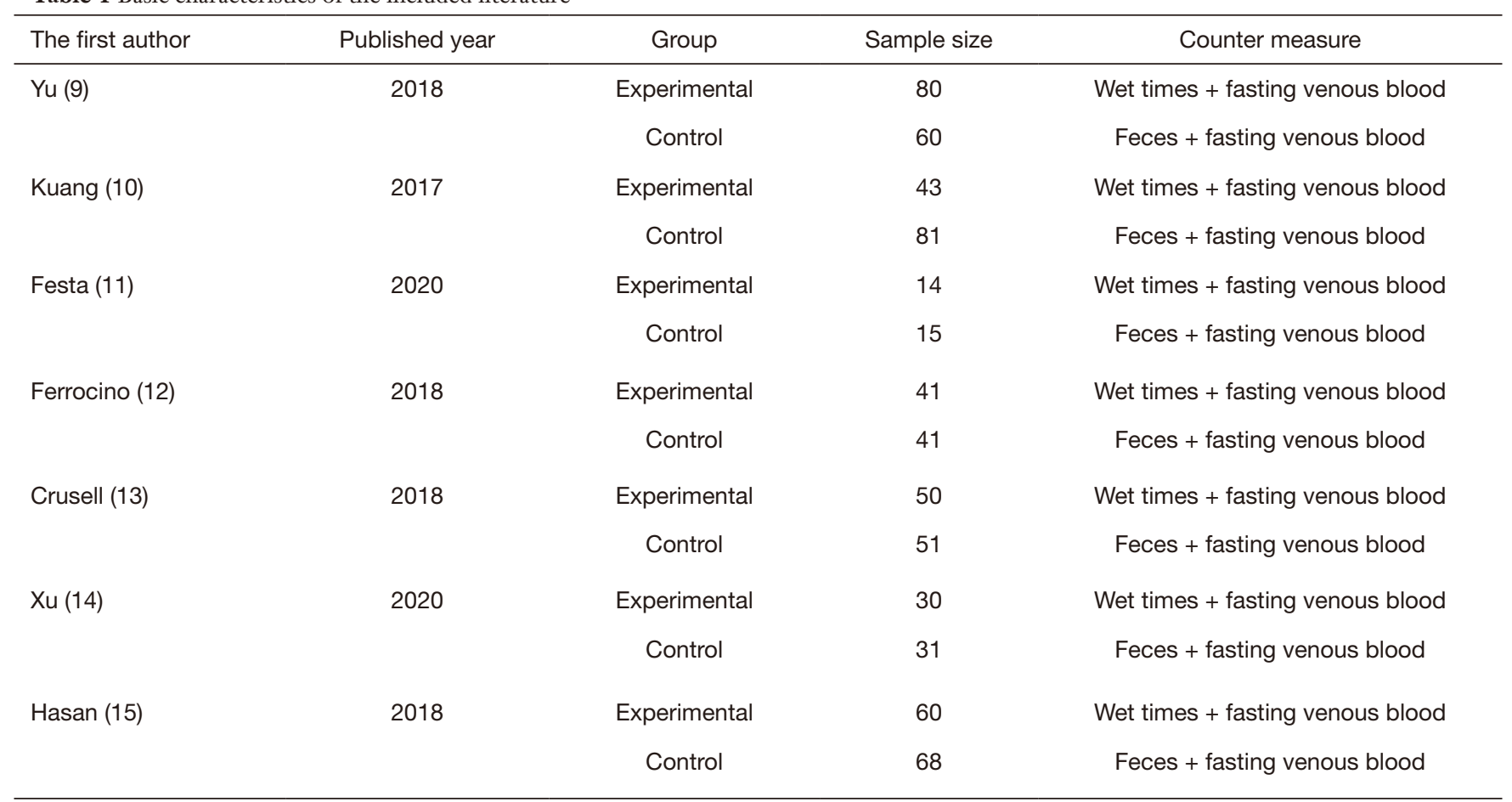

Interventions 5.0.2 was used to evaluate the bias risk of the 7 articles included in this study, and RevMan 5.3 software was used to output the bias-risk map. The assessment items included the following: (I) random sequence generation-the 7 articles (9-15) all described the specific grouping method, suggesting a low risk; (II) allocation concealment-none of the 7 articles mentioned whether "allocation concealment" had been adopted, suggesting an unclear risk; (III) blinded method for the participants-3 of the 7 articles $(11,13,15)$ mentioned that "the patient signed the informed consent form," but did not mention whether the operator was blinded or not, suggesting an unclear risk; (IV) blind method for the outcome assessor -7 articles did not mention whether the outcome assessor was blinded, suggesting an unclear risk; (V) data integrity - the outcome data of the 7 articles were complete, suggesting a low risk; (VI) selective reportthere was no selective report in the 7 articles, suggesting a low risk; (VII) other risks of bias-6 articles (9-11,13-15) had inconsistent numbers in the experimental and control groups, suggesting a high risk. It was undetermined whether the remaining 1 article (11) had other biases, suggesting an unclear risk. The results of the bias-risk assessment are shown in Figures 2 and 3.

\section{Bifidobacterium}

In this study, 5 studies $(9,10,12,13,15)$, comprising 575 cases (274 in the experimental group and 301 in the control group), it compared the intestinal Bifidobacterium in the experimental group with that of control group patients. The heterogeneity test results $\left(\mathrm{I}^{2}=99 \% ; \mathrm{P}<0.00001\right)$ suggested that there was a certain degree of heterogeneity among the studies; thus, the REM was used for the analysis. The analysis results are shown in Figure 4. The combined effect size of the meta-analysis was MD $=-2.49(95 \%$ CI: -3.54 to $-1.45 ; \mathrm{Z}=4.66 ; \mathrm{P}<0.00001)$. The diamond in the forest plot was located on the left side of the vertical line, suggesting that the GDM patients in the experimental group had a lower level of Bifidobacterium in the intestine than did those in the control group.

\section{Lactobacillus}

In this study, 3 studies $(9,11,13)$ comprising a total of 270 cases (144 in the experimental group and 126 in the control group), analyzed intestinal lactobacilli. The heterogeneity test results $\left(\mathrm{I}^{2}=0 \% ; \mathrm{P}=0.69\right)$ suggested that there was no heterogeneity among the studies; thus, the 


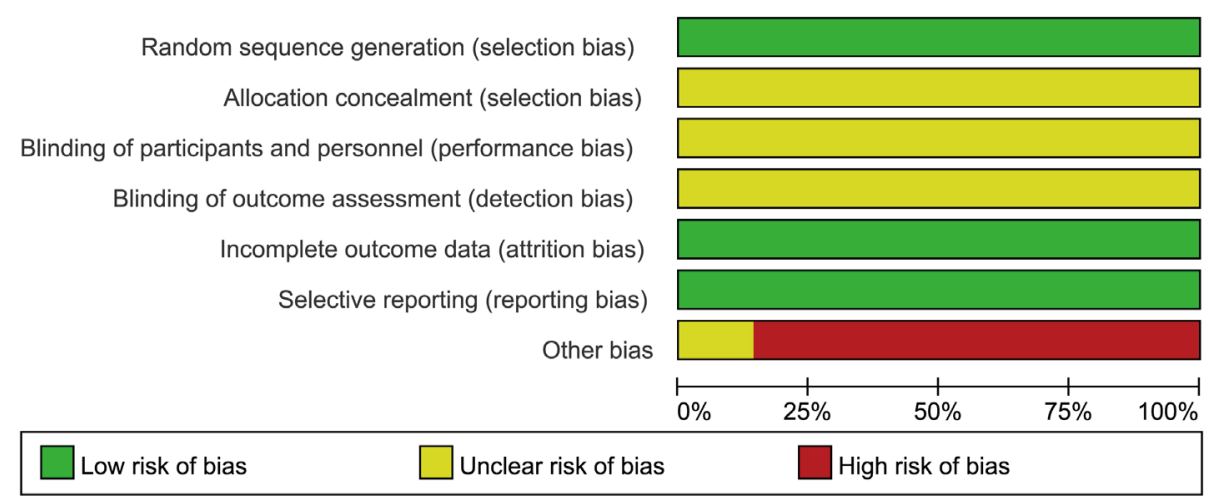

Figure 2 Bar graph of bias assessment of included documents.

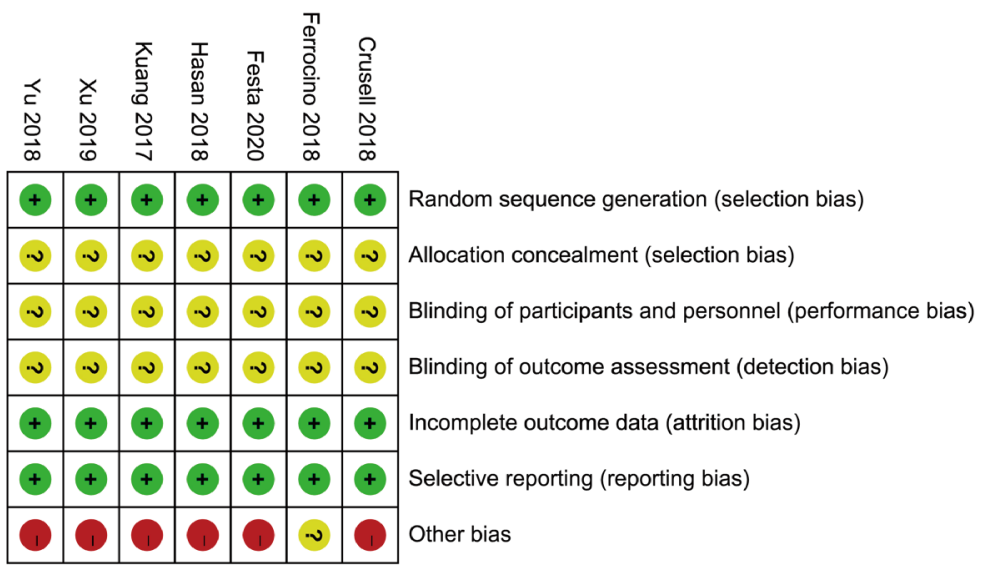

Figure 3 Bias-risk assessment of included documents.

\begin{tabular}{|c|c|c|c|c|c|c|c|c|c|c|}
\hline \multirow[b]{2}{*}{ Study or Subgroup } & \multicolumn{3}{|c|}{ Experimental } & \multicolumn{2}{|c|}{ Control } & \multirow[b]{2}{*}{ Total } & \multirow[b]{2}{*}{ Weight } & \multirow{2}{*}{$\begin{array}{l}\text { Mean Difference } \\
\text { IV. Random. } 95 \% \mathrm{Cl}\end{array}$} & \multirow{2}{*}{\multicolumn{2}{|c|}{$\begin{array}{c}\text { Mean Difference } \\
\text { IV. Random. } 95 \% \mathrm{Cl}\end{array}$}} \\
\hline & Mean & SD & Total & Mean & SD & & & & & \\
\hline Crusell 2018 & 7.04 & 0.68 & 50 & 9.13 & 0.85 & 51 & $20.0 \%$ & $-2.09[-2.39,-1.79]$ & - & \\
\hline Ferrocino 2018 & 6.3 & 0.7 & 41 & 10.4 & 0.8 & 41 & $19.9 \%$ & $-4.10[-4.43,-3.77]$ & - & \\
\hline Hasan 2018 & 7.04 & 0.96 & 60 & 9.52 & 0.85 & 68 & $19.9 \%$ & $-2.48[-2.80,-2.16]$ & - & \\
\hline Kuang 2017 & 7.1 & 0.58 & 43 & 8.1 & 0.44 & 81 & $20.2 \%$ & $-1.00[-1.20,-0.80]$ & $=$ & \\
\hline Yu 2018 & 6.83 & 0.74 & 80 & 9.65 & 0.81 & 60 & $20.0 \%$ & $-2.82[-3.08,-2.56]$ & - & \\
\hline Total $(95 \% \mathrm{Cl})$ & & & 274 & & & 301 & $100.0 \%$ & $-2.49[-3.54,-1.45]$ & & \\
\hline $\begin{array}{l}\text { Heterogeneity: } \mathrm{Tau}^{2}= \\
\text { Test for overall effect: }\end{array}$ & $\begin{array}{l}1.41 ; C h \\
Z=4.66\end{array}$ & $\begin{array}{l}i^{2}=29 \\
(P<0\end{array}$ & $\begin{array}{l}0.91, \mathrm{df} \\
00001)\end{array}$ & $f=4(P$ & $<0.0$ & $01)$ & $=99 \%$ & & $\begin{array}{cc}-4 & -2 \\
\text { [experimental] }\end{array}$ & $\begin{array}{c}2 \\
\text { [control] }\end{array}$ \\
\hline
\end{tabular}

Figure 4 Forest plot of Bifidobacterium in the intestine.

FEM was used for the analysis. The analysis results are shown in Figure 5. The combined effect size of the metaanalysis was $\mathrm{MD}=-1.69$ (95\% CI: -1.84 to -1.53 ; $\mathrm{Z}=20.66$; $\mathrm{P}<0.00001)$, and the diamond in the forest plot was located on the left side of the vertical line, suggesting that the GDM patients in the experimental group had a lower level of lactobacillus in the intestine than did those in the control group.

\section{Bacteroides}

In this study, 3 studies $(9,10,15)$, comprising a total of 


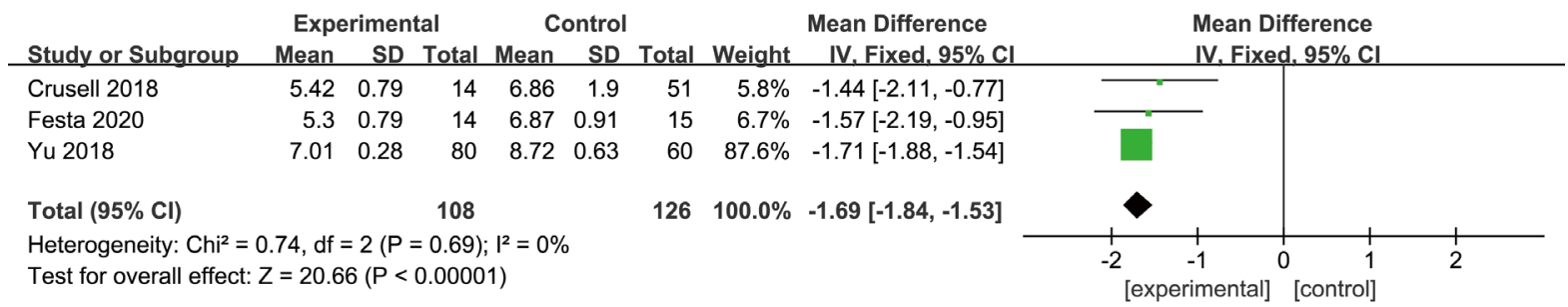

Figure 5 Forest plot of Lactobacillus in the intestine.

\begin{tabular}{|c|c|c|c|c|c|c|c|c|c|c|c|}
\hline \multirow[b]{2}{*}{ Study or Subgroup } & \multicolumn{3}{|c|}{ Experimental } & \multicolumn{2}{|c|}{ Control } & \multirow[b]{2}{*}{ Total } & \multirow[b]{2}{*}{ Weight } & \multirow{2}{*}{$\begin{array}{l}\text { Mean Difference } \\
\text { IV, Random, } 95 \% \mathrm{Cl}\end{array}$} & \multirow{2}{*}{\multicolumn{3}{|c|}{$\begin{array}{c}\text { Mean Difference } \\
\text { IV, Random, } 95 \% \mathrm{Cl}\end{array}$}} \\
\hline & Mean & SD & Total & Mean & SD & & & & & & \\
\hline Hasan 2018 & 7.92 & 0.36 & 60 & 8.86 & 0.38 & 68 & $34.7 \%$ & $-0.94[-1.07,-0.81]$ & - & & \\
\hline Kuang 2017 & 7.74 & 0.51 & 43 & 8.92 & 0.43 & 81 & $32.5 \%$ & $-1.18[-1.36,-1.00]$ & & & \\
\hline Yu 2018 & 8.27 & 0.46 & 80 & 9.68 & 0.55 & 60 & $32.8 \%$ & $-1.41[-1.58,-1.24]$ & & & \\
\hline Total $(95 \% \mathrm{Cl})$ & & & 183 & & & 209 & $100.0 \%$ & $-1.17[-1.45,-0.89]$ & & & \\
\hline $\begin{array}{l}\text { Heterogeneity: } \mathrm{Tau}^{2}= \\
\text { Test for overall effect }\end{array}$ & $\begin{array}{l}0.06 ; \mathrm{Ch} \\
Z=8.15\end{array}$ & $\begin{array}{l}i^{2}=18 \\
(P<0\end{array}$ & $\begin{array}{l}92, \mathrm{df}= \\
00001)\end{array}$ & $\begin{array}{l}=2(P \\
)\end{array}$ & 0.000 & 1) $1^{2}=$ & $89 \%$ & & $\begin{array}{lcc}1 & -1 & 0.5 \\
\text { [experimental] }\end{array}$ & $\begin{array}{r}0.5 \\
\text { [control] }\end{array}$ & 1 \\
\hline
\end{tabular}

Figure 6 Forest plot of Bacteroides in the intestine.

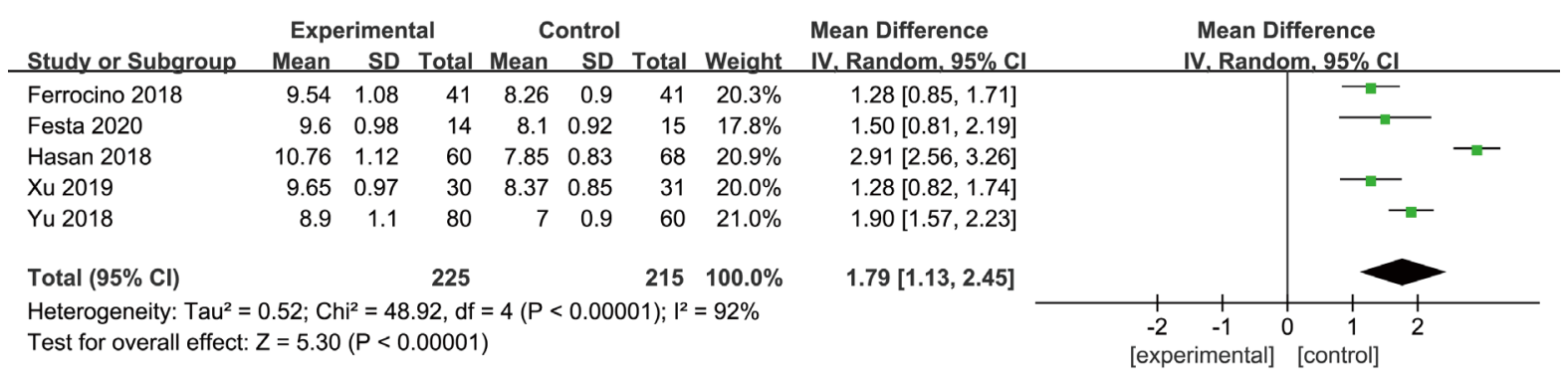

Figure 7 Forest plot of Enterobacter in the intestine.

392 cases (183 in the experimental group and 209 in the control group), analyzed the intestinal Bacteroides of patients. The heterogeneity test results $\left(\mathrm{I}^{2}=89 \% ; \mathrm{P}<0.0001\right)$ suggested that there was heterogeneity among the studies; thus, the REM was used for the analysis. The analysis results are shown in Figure 6. The combined effect size of the meta-analysis was $\mathrm{MD}=-1.17$ (95\% CI: -1.45 to -0.89 ; $\mathrm{Z}=8.15 ; \mathrm{P}<0.00001)$. The diamond in the forest diagram was on the left side of the vertical line, suggesting that the GDM patients in the experimental group had a lower level of Bacteroides in the intestine than did those in the control group.

\section{Enterobacter}

In this study, 5 studies $(9,11,12,14,15)$ comprising
440 cases (225 in the experimental group and 215 in the control group) analyzed intestinal Enterobacter. The heterogeneity test results $\left(\mathrm{I}^{2}=92 \% ; \mathrm{P}<0.00001\right)$ indicated that there was heterogeneity among the studies; thus, the REM was used for the analysis. The analysis results are shown in Figure 7. The combined effect size of the metaanalysis was $\mathrm{MD}=1.79$ (95\% CI: 1.13 to $2.45 ; Z=5.3$; $\mathrm{P}<0.00001)$, and the diamond in the forest plot was located on the right side of the vertical line, suggesting that the GDM patients in the experimental group had a higher level of Enterobacter than did those in the control group.

\section{Enterococcus}

In this study, 3 studies $(12,13,15)$ comprising a total of 


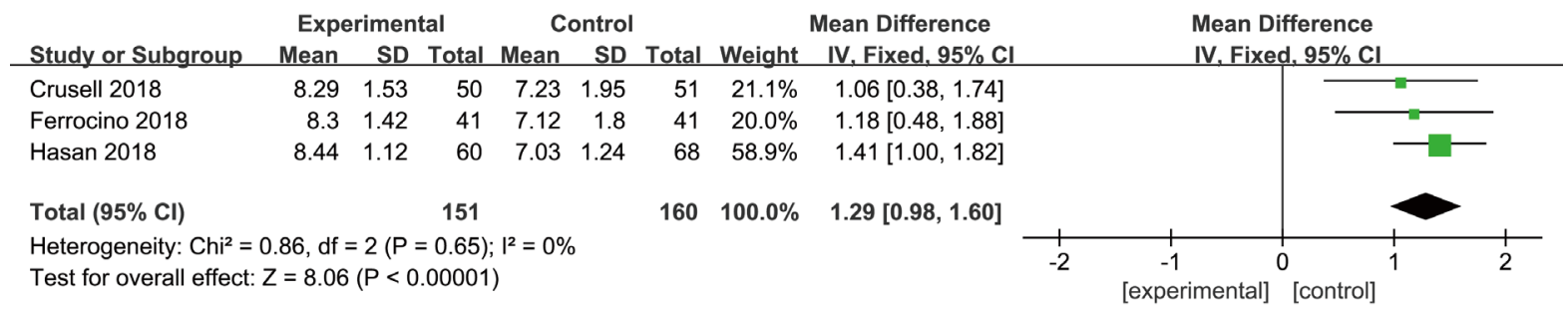

Figure 8 Forest plot of Enterococcus in the intestine.

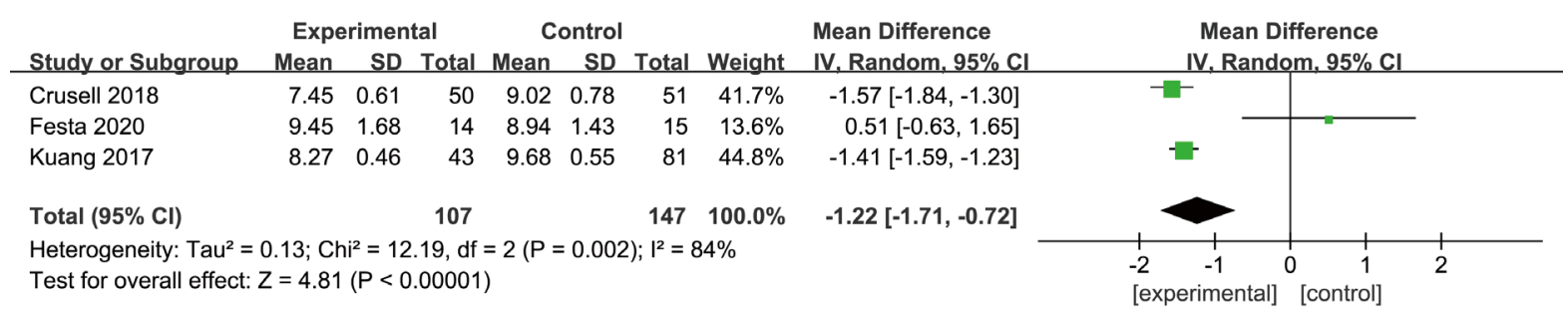

Figure 9 Forest plot of Bacteroidetes in the intestine.

311 cases (151 in the experimental group and 160 in the control group) analyzed intestinal enterococci. The heterogeneity test results $\left(I^{2}=0 \% ; P=0.65\right)$ suggested that there was no heterogeneity among the studies; thus, the FEM was used for the analysis. The analysis results are shown in Figure 8. The combined effect size of the metaanalysis was $\mathrm{MD}=1.29$ (95\% CI: 0.98 to $1.6 ; Z=8.06$; $\mathrm{P}<0.00001)$. The diamond in the forest plot was located on the right side of the vertical line, suggesting that the GDM patients in the experimental group had a higher level of Enterococcus in the intestine than those in the control group.

\section{Bacteroidetes}

In this study, 3 studies $(10,11,13)$ comprising a total of 254 cases (107 in the experimental group and 147 in the control group) analyzed intestinal Bacteroidetes. The heterogeneity test results $\left(I^{2}=84 \% ; P=0.002\right)$ suggested that there was a certain degree of heterogeneity among the studies; thus, the REM was used for the analysis. The analysis results are shown in Figure 9. The combined effect size of the meta-analysis was MD $=-1.22(95 \% \mathrm{CI}:-1.71$ to $-0.72 ; Z=4.81 ; P<0.00001)$. The diamond in the forest plot was located on the left side of the vertical line, suggesting that the GDM patients in the experimental group had a lower level of Bacteroidetes in the intestine did than those in the control group.

\section{Fusobacterium}

In the study, 3 studies $(12,13,15)$, comprising a total of 311 cases (151 in the experimental group and 160 in the control group), analyzed intestinal fusobacterium. The heterogeneity test results $\left(\mathrm{I}^{2}=0 \% ; \mathrm{P}=0.86\right)$ suggested there to be no heterogeneity among the studies; thus, the FEM was used for the analysis. The analysis results are shown in Figure 10. The combined effect size of the meta-analysis was $\mathrm{MD}=0.03$ (95\% CI: -0.13 to $0.19 ; \mathrm{Z}=0.37 ; \mathrm{P}=0.71$ ). The diamond in the forest plot was located on the right side of the vertical line, suggesting that the GDM patients in the experimental group had a lower level of Fusobacterium than did those in the control group.

\section{Tumor necrosis factor alpha}

In this study, 4 studies $(9,11,12,14)$, comprising a total of 312 cases (165 in the experimental group and 147 in the control group), analyzed the level of tumor necrosis factor alpha $(\mathrm{TNF}-\alpha)$. The heterogeneity test results $\left(\mathrm{I}^{2}=100 \%\right.$; $\mathrm{P}<0.00001)$ suggested that there was a certain degree of heterogeneity among the studies; thus, the REM was used for the analysis. The analysis results are shown in Figure 11. The combined effect size of the meta-analysis was $\mathrm{MD}=113.66$ (95\% CI: 52.01 to $175.31 ; \mathrm{Z}=3.61 ; \mathrm{P}=0.0003$ ). The diamond in the forest plot was located on the right side 


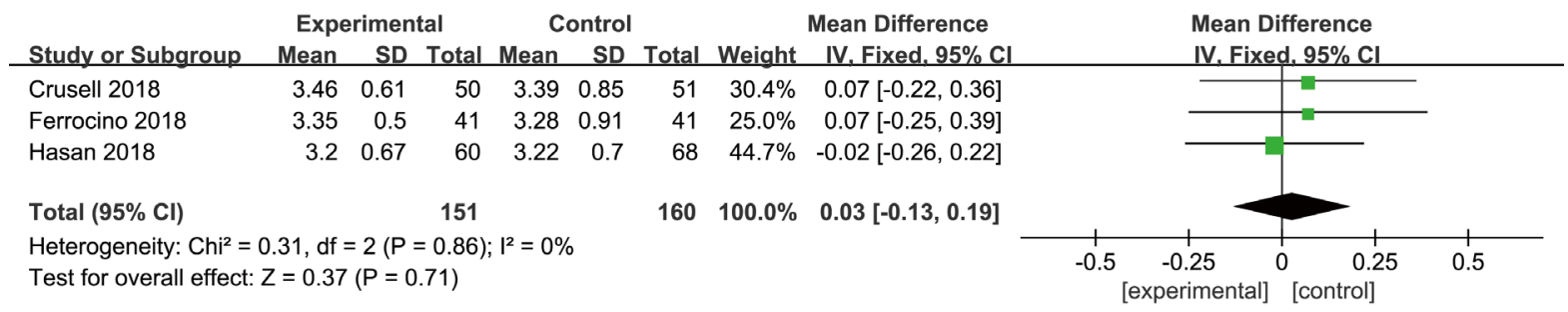

Figure 10 Forest plot of Fusobacterium in the intestine.

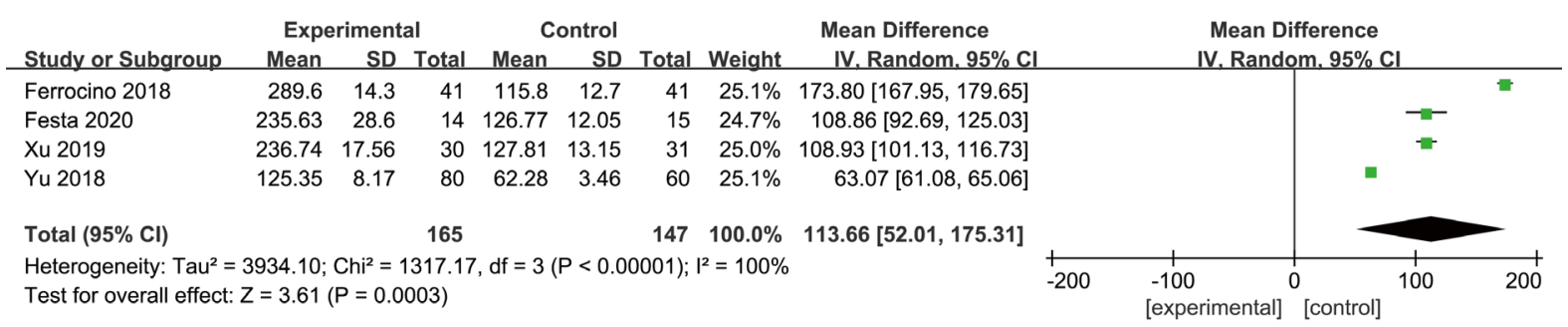

Figure 11 Forest plot of tumor necrosis factor alpha in the intestine.

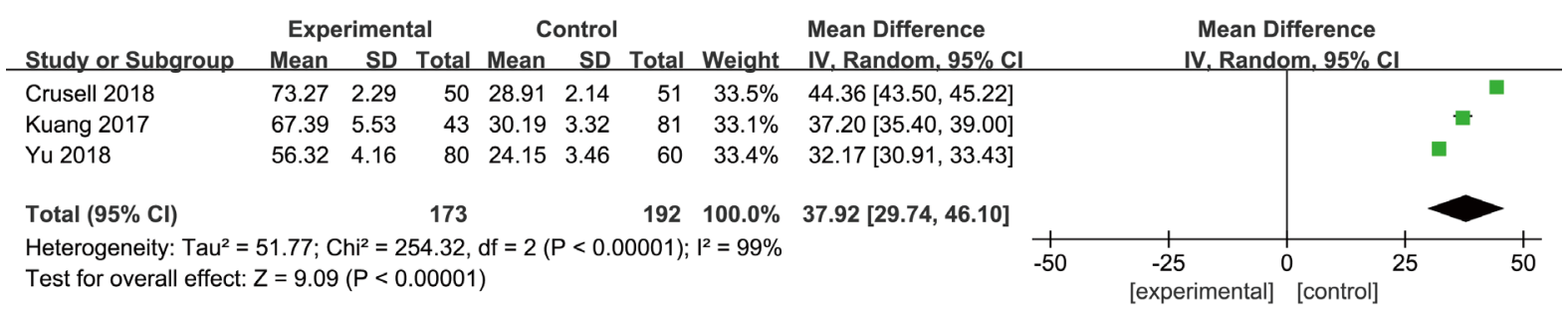

Figure 12 Forest plot of interleukin 17 in the intestine.

of the vertical line, suggesting that the GDM patients in the experimental group had a higher level of TNF- $\alpha$ in the intestine than did those in the control group.

\section{Interleukin 17}

In this study, 3 studies $(9,10,13)$, comprising a total of 365 cases (173 in the experimental group and 132 in the control group) analyzed the level of interleukin (IL)-17. The heterogeneity test results $\left(\mathrm{I}^{2}=99 \% ; \mathrm{P}<0.00001\right)$ suggested that there was heterogeneity among the studies; thus, the REM was used for the analysis. The analysis results are shown in Figure 12. The combined effect size of the metaanalysis was $\mathrm{MD}=37.92 ; 95 \% \mathrm{CI}$ : 29.74 to $46.1 ; Z=9.09$; $\mathrm{P}<0.00001]$. The diamond in the forest plot was located on the right side of the vertical line, suggesting that the GDM patients in the experimental group had a higher level of IL-17 than did those in the control group.

\section{Interleukin 6}

In this study, 3 studies $(9,10,12)$, comprising a total of 346 cases (164 in the experimental group and 182 in the control group), analyzed the level of IL-6. The heterogeneity test results $\left(\mathrm{I}^{2}=100 \% ; \mathrm{P}<0.00001\right)$ suggested that there was heterogeneity among the studies; thus, the REM was used for the analysis. The analysis results are shown in Figure 13. The combined effect size of the metaanalysis was $\mathrm{MD}=66.38$ (95\% CI: 33.6 to $99.15 ; \mathrm{Z}=3.97$; $\mathrm{P}<0.0001)$. The diamond in the forest plot was located on the right side of the vertical line, suggesting that the GDM patients in the experimental group had a higher level of 


\begin{tabular}{|c|c|c|c|c|c|c|c|c|c|c|c|c|}
\hline \multirow[b]{2}{*}{ Study or Subgroup } & \multicolumn{3}{|c|}{ Experimental } & \multicolumn{2}{|c|}{ Control } & \multirow[b]{2}{*}{ Total } & \multirow{2}{*}{\multicolumn{2}{|c|}{$\begin{array}{cl} & \text { Mean Difference } \\
\text { Weight } & \text { IV.Random, } 95 \% \mathrm{Cl} \\
\end{array}$}} & \multirow{2}{*}{\multicolumn{3}{|c|}{$\begin{array}{l}\text { Mean Difference } \\
\text { IV, Random, } 95 \% \mathrm{Cl}\end{array}$}} & \\
\hline & Mean & SD & Total & Mean & SD & & & & & & & \\
\hline Ferrocino 2018 & 185.23 & 20.27 & 41 & 97.43 & 21.12 & 41 & $32.8 \%$ & $87.80[78.84,96.76]$ & & & & -1 \\
\hline Kuang 2017 & 152.7 & 11.6 & 43 & 77.44 & 9.55 & 81 & $33.5 \%$ & $75.26[71.22,79.30]$ & & & - & \\
\hline Yu 2018 & 59.44 & 3.95 & 80 & 22.81 & 1.54 & 60 & $33.7 \%$ & $36.63[35.68,37.58]$ & & & - & \\
\hline Total $(95 \% \mathrm{Cl})$ & & & 164 & & & 182 & $100.0 \%$ & $66.38[33.60,99.15]$ & & & & \\
\hline $\begin{array}{l}\text { Heterogeneity: } \mathrm{Tau}^{2}= \\
\text { Test for overall effect }\end{array}$ & $\begin{array}{l}830.60 ; C \\
Z=3.97\end{array}$ & $\begin{array}{l}\mathrm{hi}^{2}=44 \\
\mathrm{P}<0.0\end{array}$ & $\begin{array}{l}6.74, \mathrm{c} \\
01)\end{array}$ & If $=2(P$ & 0.00 & 1); $\left.\right|^{2}$ & $=100 \%$ & & $\begin{array}{r}-100 \\
{[e x}\end{array}$ & $\begin{array}{ll}-50 & 0 \\
\text { erimental] }\end{array}$ & $\begin{array}{r}50 \\
\text { [control] }\end{array}$ & 100 \\
\hline
\end{tabular}

Figure 13 Forest plot of interleukin 6 in the intestine.

IL-6 than did those in the control group.

\section{Publication bias}

RevMan 5.3 software was used to evaluate the publication bias. The analysis results are shown in Figure 14. The points of Bifidobacterium, Lactobacillus, Enterococcus, Bacteroidetes, and Fusobacterium was basically distributed within the CI, and the literature bias was low, while the points of Bacteroides, Enterobacter, TNF- $\alpha$, IL-17, and IL-6 were distributed out of the CI, and the distribution was scattered, indicating that there was a certain publication bias in the included literature.

\section{Discussion}

With the shift in lifestyle of modern society, the intake of high-energy diets during pregnancy, and the changes in the metabolism of pregnant women during pregnancy, the incidence of GDM has increased year by year $(16,17)$. Intestinal flora refers to the bacteria that inhabit the human gastrointestinal tract, which has done since the beginning of the human species, gradually developing into normal flora. Intestinal flora mainly colonizes the colon and depends on the digestion of food residues to meet the energy needs of survival (18-20). There are about $10^{14}$ microorganisms in the human intestine, which is about 10 times the total number of human cells, and they participate in the body's carbohydrate metabolism, fat metabolism, and other physiological processes (21). Imbalance of the intestinal flora causes changes in the proportion of the flora, increases the permeability of the intestinal wall, and produces many inflammatory factors (22). In addition to having reasonable dietary structure, the main way for pregnant women to improve their intestinal flora is to adjust the intestinal environment and prevent problems by using dietary supplements (23). Probiotics have two basic functions: one is to balance the intestinal flora, maintain healthy active microorganisms in the intestine, and promote intestinal peristalsis; the other is to stimulate the intestinal immune function and enhance immunity. For pregnant women, studies have shown that probiotics can reduce the incidence of GDM, improve maternal immunity, and regulate the body's absorption of sugars, lipids, and other substances in food (24). A previous endotoxin theory contended that physiological changes during pregnancy lead to changes of dietary habits to varying degrees. Dietary habits largely affect the composition of the intestinal flora, and the composition of the intestinal flora is associated with the intestinal barrier function (25-27). For example, a long-term high-fat diet during pregnancy decreases the expression of tight junction proteins in intestinal epithelial cells and increases the permeability of the intestinal mucosa so that a large amount of bacterial lipopolysaccharide is released into the blood, activating the low-grade chronic inflammation of islets. Inflammation can lead to the structural damage and dysfunction of pancreatic islet B cells, promote B cell apoptosis, and cause insufficient insulin secretion; longterm low-grade inflammation leads to weakened insulin signal transduction and sensitivity, which in turn triggers GDM (28).

To systematically analyze the relationship between intestinal flora and GDM, a total of 7 reports were included in this meta-analysis. It was found that, except for Bifidobacterium, Lactobacillus, Bacteroides, and Bacteroidetes, whose diamonds were located on the left side, the indicators had diamonds located on the right side, suggesting that the intestinal flora was associated with the occurrence of GDM. Bifidobacterium and Lactobacillus, as human probiotics, mainly regulate intestinal microbial disorders. When GDM occurs, the relative levels of the 2 decrease, while the relative levels of Enterobacter and Enterococcus increase. It has been speculated that changes in the level of probiotics, such as in Bifidobacterium and Lactobacillus, may be an important internal factor for the occurrence of GDM due to the intestinal flora (29). Additionally, the changes of Bacteroidetes and Fusobacteria did not show specificity in this meta-analysis; 

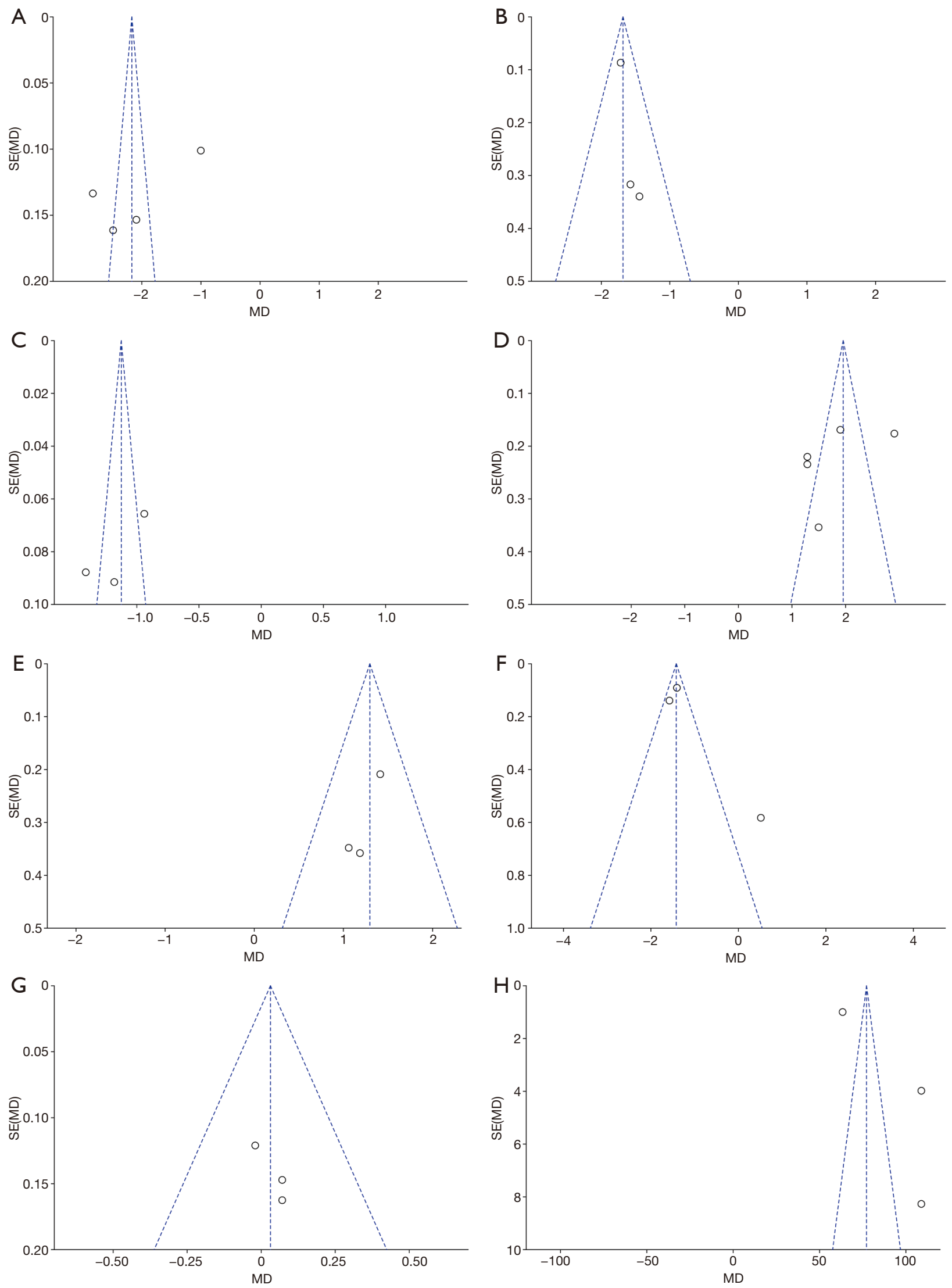

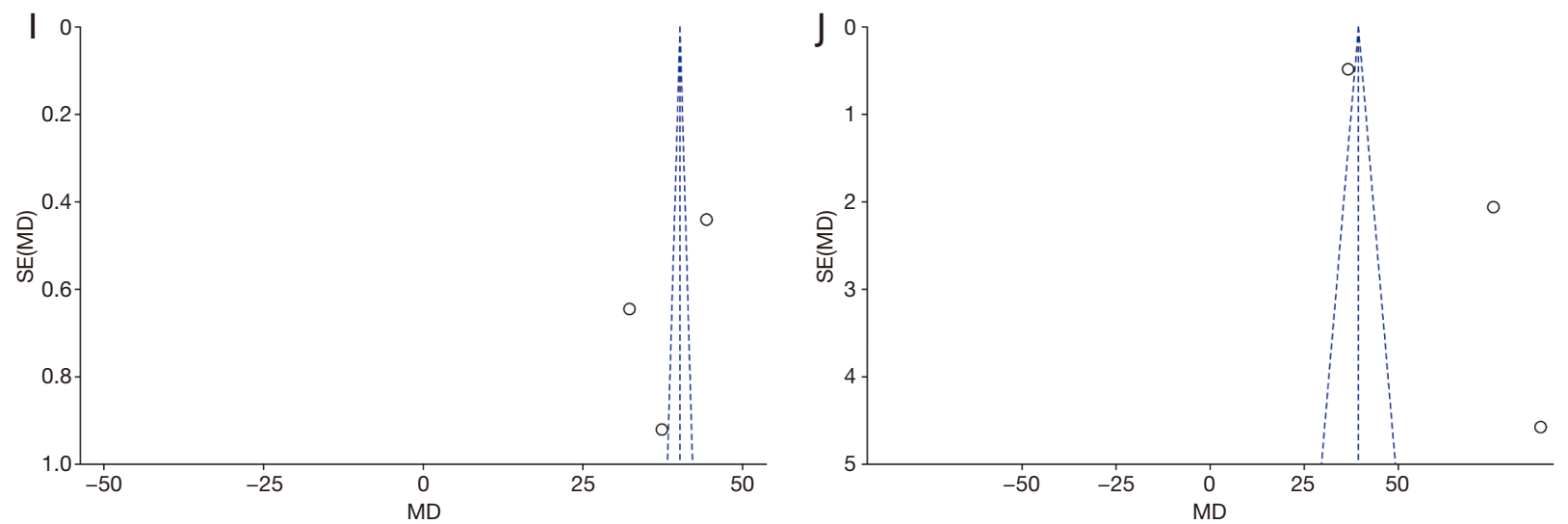

Figure 14 Funnel chart of all indicators involved in the study. (A) Bifidobacterium; (B) Lactobacillus; (C) Bacteroides; (D) Enterobacter; (E) Enterococcus; (F) Bacteroidetes; (G) Fusobacterium; (H) TNF- $\alpha$; (I) IL-17; (J) IL-6. TNF, tumor necrosis factor alpha; IL, interleukin.

however, previous studies have found that the structural changes of Clostridium sphaericus and Bacteroidetes polymorpha are correlated with the occurrence of GDM (30). TNF- $\alpha$, IL-17, and IL-6 are all inflammatory factors. Studies have shown that these inflammatory factors are directly related to inflammatory bowel disease (31). They can promote the shedding of colonic epithelial cells and participate in the inflammatory response of the lamina propria, thereby increasing the permeability of cells in the colon.

\section{Conclusions}

In this meta-analysis on the correlation between intestinal flora with GDM, a total of 7 studies were included, comprising 665 cases. It was found that changes in the intestinal microecology were closely related to the occurrence of GDM, which mainly manifested as a decrease in the level of probiotics, an increase in the level of intestinal bacteria and other strains, and an increase in the level of inflammatory factors. However, the limitations of this meta-analysis should be noted. Some studies had a large publication bias. Further, some analysis indicators contained a small number of samples, and the meta-analysis results were not sufficiently accurate. Thus, in follow-up research, studies with larger sample sizes and of a high quality need to be included to verify the association between GDM and intestinal flora.

\section{Acknowledgments}

Funding: None.

\section{Footnote}

Reporting Checklist: The authors have completed the PRISMA reporting checklist. Available at https://dx.doi. org/10.21037/apm-21-2061

Conflicts of Interest: All authors have completed the ICMJE uniform disclosure form (available at https://dx.doi. org/10.21037/apm-21-2061). The authors have no conflicts of interest to declare.

Ethical Statement: The authors are accountable for all aspects of the work in ensuring that questions related to the accuracy or integrity of any part of the work are appropriately investigated and resolved.

Open Access Statement: This is an Open Access article distributed in accordance with the Creative Commons Attribution-NonCommercial-NoDerivs 4.0 International License (CC BY-NC-ND 4.0), which permits the noncommercial replication and distribution of the article with the strict proviso that no changes or edits are made and the original work is properly cited (including links to both the formal publication through the relevant DOI and the license). See: https://creativecommons.org/licenses/by-nc-nd/4.0/.

\section{References}

1. Johns EC, Denison FC, Norman JE, et al. Gestational Diabetes Mellitus: Mechanisms, Treatment, and Complications. Trends Endocrinol Metab 2018;29:743-54.

2. Yuan $\mathrm{K}$, Wang $\mathrm{H}$, Chen $\mathrm{Y}$, et al. A 12-hour comprehensive 
nutrition care benefits blood glucose level and weight gain and improves outcomes in pregnant women with gestational diabetes mellitus.

Ann Palliat Med 2020;9:661-70.

3. ACOG Practice Bulletin No. 190 Summary: Gestational Diabetes Mellitus. Obstet Gynecol 2018;131:406-8.

4. Homayouni A, Bagheri N, Mohammad-AlizadehCharandabi S, et al. Prevention of Gestational Diabetes Mellitus (GDM) and Probiotics: Mechanism of Action: A Review. Curr Diabetes Rev 2020;16:538-45.

5. Immanuel J, Simmons D. Screening and Treatment for Early-Onset Gestational Diabetes Mellitus: a Systematic Review and Meta-analysis. Curr Diab Rep 2017;17:115.

6. Agha-Jaffar R, Oliver N, Johnston D, et al. Gestational diabetes mellitus: does an effective prevention strategy exist? Nat Rev Endocrinol 2016;12:533-46.

7. Świrska J, Zwolak A, Dudzińska M, et al. Gestational diabetes mellitus - literature review on selected cytokines and hormones of confirmed or possible role in its pathogenesis. Ginekol Pol 2018;89:522-7.

8. Cortez RV, Taddei CR, Sparvoli LG, et al. Microbiome and its relation to gestational diabetes. Endocrine 2019;64:254-64.

9. Yu H, Liu Z, Dong S. Changes in Intestinal Flora, TNF- $\alpha$, L-17, and IL-6 Levels in Patients with Gestational Diabetes Mellitus. European Journal of Inflammation 2018;16:2058739218793550.

10. Kuang YS, Lu JH, Li SH, et al. Connections between the human gut microbiome and gestational diabetes mellitus. Gigascience 2017;6:1-12.

11. Festa C, Drago L, Martorelli M, et al. Flash on gut microbiome in gestational diabetes: a pilot study. New Microbiol 2020;43:195-7.

12. Ferrocino I, Ponzo V, Gambino R, et al. Changes in the gut microbiota composition during pregnancy in patients with gestational diabetes mellitus (GDM). Sci Rep 2018;8:12216.

13. Crusell MKW, Hansen TH, Nielsen T, et al. Gestational diabetes is associated with change in the gut microbiota composition in third trimester of pregnancy and postpartum. Microbiome 2018;6:89.

14. Xu Y, Zhang M, Zhang J, et al. Differential intestinal and oral microbiota features associated with gestational diabetes and maternal inflammation. Am J Physiol Endocrinol Metab 2020;319:E247-53.

15. Hasan S, Aho V, Pereira P, et al. Gut microbiome in gestational diabetes: a cross-sectional study of mothers and offspring 5 years postpartum. Acta Obstet Gynecol Scand
2018;97:38-46.

16. Filardi T, Panimolle F, Crescioli C, et al. Gestational Diabetes Mellitus: The Impact of Carbohydrate Quality in Diet. Nutrients 2019;11:1549.

17. Moon JH, Kwak SH, Jang HC. Prevention of type 2 diabetes mellitus in women with previous gestational diabetes mellitus. Korean J Intern Med 2017;32:26-41.

18. Law KP, Zhang H. The pathogenesis and pathophysiology of gestational diabetes mellitus: Deductions from a threepart longitudinal metabolomics study in China. Clin Chim Acta 2017;468:60-70.

19. Buckley BS, Harreiter J, Damm P, et al. Gestational diabetes mellitus in Europe: prevalence, current screening practice and barriers to screening. A review. Diabet Med 2012;29:844-54.

20. Abell SK, De Courten B, Boyle JA, et al. Inflammatory and Other Biomarkers: Role in Pathophysiology and Prediction of Gestational Diabetes Mellitus. Int J Mol Sci 2015;16:13442-73.

21. Juan J, Yang H. Prevalence, Prevention, and Lifestyle Intervention of Gestational Diabetes Mellitus in China. Int J Environ Res Public Health 2020;17:9517.

22. Edwards SM, Cunningham SA, Dunlop AL, et al. The Maternal Gut Microbiome During Pregnancy. MCN Am J Matern Child Nurs 2017;42:310-7.

23. Gomez-Arango LF, Barrett HL, Wilkinson SA, et al. Low dietary fiber intake increases Collinsella abundance in the gut microbiota of overweight and obese pregnant women. Gut Microbes 2018;9:189-201.

24. Yang H, Guo R, Li S, et al. Systematic analysis of gut microbiota in pregnant women and its correlations with individual heterogeneity. NPJ Biofilms Microbiomes 2020;6:32.

25. Moreno-Castilla C, Mauricio D, Hernandez M. Role of Medical Nutrition Therapy in the Management of Gestational Diabetes Mellitus. Curr Diab Rep 2016;16:22.

26. $\mathrm{Xu} \mathrm{T}, \mathrm{He} \mathrm{Y}$, Dainelli L, et al. Healthcare interventions for the prevention and control of gestational diabetes mellitus in China: a scoping review. BMC Pregnancy Childbirth 2017;17:171.

27. Pan J, Pan Q, Chen Y, et al. Efficacy of probiotic supplement for gestational diabetes mellitus: a systematic review and meta-analysis. J Matern Fetal Neonatal Med 2019;32:317-23.

28. Hod M, Kapur A, McIntyre HD, et al. Evidence in support of the International Association of Diabetes in Pregnancy study groups' criteria for diagnosing gestational diabetes mellitus worldwide in 2019. Am J Obstet Gynecol 
2019;221:109-16.

29. Blumberg J, Ballares V, Durbin JL. Ethnic variations on gestational diabetes mellitus and evidence-based first-line interventions. J Matern Fetal Neonatal Med 2018;31:2641-7.

30. Li G, Yin P, Chu S, et al. Correlation Analysis between GDM and Gut Microbial Composition in Late Pregnancy.
J Diabetes Res 2021;2021:8892849.

31. Hu P, Chen X, Chu X, et al. Association of Gut Microbiota during Early Pregnancy with Risk of Incident Gestational Diabetes Mellitus. J Clin Endocrinol Metab 2021:dgab346.

(English Language Editor: L. Huleatt)

Cite this article as: Ding Q, Hu Y, Fu Y, Qian L. Systematic review and meta-analysis of the correlation between intestinal flora and gestational diabetes mellitus. Ann Palliat Med 2021;10(9):9752-9764. doi: 10.21037/apm-21-2061 